\title{
Characteristics and Factors Associated With Antihypertensive Medication Use in Patients Attending Peruvian Health Facilities
}

Christian R. Mejia ${ }^{1}$, Virgilio E. Failoc-Rojas ${ }^{2}$, Edison So ${ }^{3}$, Carmen Cervantes ${ }^{4}$, Antonio J. Aspajo ${ }^{5}$, Jesus Galileo Leandro ${ }^{6}$, Jhomar Cordova-De La Cruz ${ }^{6}$, Julio C. Charri ${ }^{6}$, Kevin E. García-Auqui $^{7}$, Lelis Gabriela Coronel-Chucos ${ }^{8}$, Luz Delia Justo-Pinto ${ }^{9}$, Marisol Stefanie Mamani-Apaza ${ }^{9}$, Neil A. Paz-Campos ${ }^{10}$, Ricardo Correa ${ }^{11}$

1. Escuela de Medicina Humana, Universidad Continental, Huancayo, Peru 2. Medicine, Universidad Nacional Pedro Ruiz Gallo. Lambayeque, Peru 3. Endocrinology and Metabolism, The Warren Alpert Medical School of Brown University 4. Medicine, Aventura Hospital 5. Medicine, Universidad Nacional de la Amazonía Peruana. Loreto, Peru. 6. Medicine, Universidad Nacional Daniel Alcides Carrión. Cerro de Pasco, Peru. 7. Medicine, Sociedad Científica de Estudiantes de Medicina del Centro, Universidad Nacional del Centro del Perú. Huancayo, Junín, Perú. 8. Medicine, Escuela Académico Profesional de Medicina Humana, Universidad Continental. Huancayo, Junín, Perú. 9. Medicine, Facultad de medicina, Universidad Nacional del Altiplano, Puno, Peru 10. Facultad de Medicina Humana, Universidad Peruana Los Andes 11. NICHD, National Institute of Health

$\square$ Corresponding author: Edison So, paladdinx2013@gmail.com

Disclosures can be found in Additional Information at the end of the article

\section{Abstract}

\section{Introduction}

Hypertension is a very common disease worldwide, and medication is needed to prevent its short-term and long-term complications. Our objective was to determine the characteristics and factors associated with antihypertensive medication use in patients attending Peruvian health facilities.

\section{Materials \& Methods}

We performed a multicenter, cross-sectional study with secondary data. We obtained selfreported antihypertensive medication from patients attending health facilities in 10 departments of Peru. We looked for associations of the antihypertensive treatment according to sociopathological factors and obtained p values using generalized linear models.

Received 12/20/2016 Review began 01/10/2017 Review ended 01/23/2017 Published 02/03/2017

C) Copyright 2017

Mejia et al. This is an open access article distributed under the terms of the Creative Commons Attribution License CC-BY 3.0., which permits unrestricted use, distribution, and reproduction in any medium, provided the original author and source are credited.

\section{Results}

Of the 894 patients with hypertension, 61\% (547) were women and 60\% (503) were on antihypertensive treatment, of which $82 \%$ (389) had monotherapy and 52\% (258) had recently taken their medication. Antihypertensive treatment was positively correlated with the patient's age (adjusted prevalence ratio [aPR]: 1.01; 95\% confidence interval [CI]: 1.007 to 1.017; $p$ value $<0.001$ ), diabetes (aPR: 1.31 ; 95\% CI: 1.11 to 1.55 ; $\mathrm{p}$ value $=0.001$ ) and cardiovascular disease (aPR: 1.38 ; 95\% CI: 1.26 to 1.51 ; p value < 0.001 ). Conversely, the frequency of antihypertensive treatment decreases with physical activity (aPR: 0.80 ; $95 \% \mathrm{CI}: 0.70$ to 0.92 ; $\mathrm{p}$ value $=0.001$ ).

\section{Conclusion}


Patients who have comorbidities and advanced age are more likely to be on antihypertensive treatment. In contrast, patients with increased physical activity have a lower frequency of antihypertensive treatment. It is important to consider these factors for future preventive programs and to improve therapeutic compliance.

Categories: Medical Education, Preventive Medicine, Epidemiology/Public Health Keywords: hypertension, pharmacologic treatment, multicenter, peru

\section{Introduction}

The complications of high blood pressure, if not addressed, promptly become the leading cause of death worldwide [1-2]. Treatment ranges from lifestyle modifications [3] to pharmacologic therapy [4]. Specific blood pressure targets should be achieved according to age and comorbidities [5] because the excessive reduction is also associated with increased morbidity and mortality [6]. This represents a current large-scale medical challenge. The inadequate control of high blood pressure worldwide has led to increased cardiovascular events [7-8] and/or damage to target organs [9]. Almost half of hypertensive patients are not on treatments, and a higher proportion of patients with hypertension, diabetes, and kidney disease are not on treatment. Therefore, a simple treatment is recommended to improve compliance [10] and early initiation of medication for higher risk patients [11].

Most studies on this subject, especially in our environment, address factors associated with hypertension and its consequences $[5,12]$. Identifying factors associated with the use of antihypertensive medications is necessary for professionals and institutions involved to manage this population properly [13]. Therefore, multinational institutions have established objectives that promote research focused on the prevention and control of noncommunicable diseases [14]. Hence, the aim of this study is to determine the characteristics and factors associated with antihypertensive medication use in patients attending Peruvian health care facilities.

\section{Materials And Methods}

\section{Study design}

An analytical transversal study derived from secondary data was performed. The main objective was to determine the characteristics and factors associated with antihypertensive medication use in patients attending Peruvian health facilities.

\section{Population and sample}

Data were obtained from patient surveys in health facilities in the following cities of Peru: Piura, Chiclayo, Lima, Huancayo, Iquitos, Cajamarca, Huanuco, Cusco, Puno, Cerro de Pasco, and Rinconada-Puno. The samples were not randomized. Data from all adult patients who answered the questionnaire voluntarily were included as well as those with a prior diagnosis of hypertension (to determine the amount of and associated factors with medication). People who did not answer medication-related questions were excluded.

\section{Variables}

The primary endpoint was receiving antihypertensive medication. This information was obtained from the main database by asking if the person had any drug to control blood pressure (response categories: YES or NO). Other variables considered to characterize medication were the number of drugs taken (by specifying all drugs that they took) and if they had taken any 


\section{Cureus}

medication on the day of the survey.

With regard to factors associated with medication, we included: gender (male/female), age (a quantitative variable considered for the analysis), medical condition, treatment of comorbidities (diabetes mellitus, heart disease, hypercholesterolemia, and hypertriglyceridemia), and performance of physical activity or any sports (corroborated by asking type, years, and hours practiced per month). All these data were taken from the database, which was built from self-reports.

\section{Ethics and procedures}

Primary research was accepted by the institutional review board (IRB) of the Hospital Nacional San Bartolome and Hospital Regional de Lambayeque, entities accredited by the Instituto Nacional de Salud. Informed patient consent was obtained. After receiving the database, quality control was performed separately by two authors, who compared the database data with the survey data and merged it into one database (for a subsequent review if data matched). All this was done in an Excel 2010 data sheet (Microsoft, Redmond, Washington, USA). Following this, we performed statistical analysis.

\section{Analysis of data}

The data were processed statistically in Stata software, version 11.1 (StataCorp, College Station, Texas, USA). For the description of the numerical variable age, its normality was determined with the Shapiro-Wilk statistical test, which allowed the establishment of median and ranges. For the description of categorical variables, frequencies and percentages were used.

For bivariate analysis, we obtained p values, crude prevalence ratios (cPRs), aPRs, and 95\% CIs. Generalized linear models were used with Poisson distribution and log link function. Also, we considered the uniqueness of the surveyed populations, so we used the headquarters of the respondent as a cluster. To avoid nonconvergence in the multivariate analysis, we included medication for each comorbidity and physical activity in the final model (independent from medical conditions or sport). Confidence intervals of $95 \%$ and $p$ values $<0.05$ were recognized as statistically significant.

\section{Results}

Out of the 894 patients with hypertension, 61\% (547) were women, and the median age was 57 years. Sixty percent (503) of patients were recorded to be receiving antihypertensive treatment; among this group, 82\% (389) were on monotherapy, and 52\% (258) had recently taken their medication (Table 1).

\begin{tabular}{|c|c|c|}
\hline Variable & $\mathbf{N}$ & $\%$ \\
\hline \multicolumn{3}{|l|}{ Gender } \\
\hline Female & 547 & 61.2 \\
\hline Male & 347 & 38.8 \\
\hline Age (years)* & 57 & $18-93$ \\
\hline \multicolumn{3}{|c|}{ Receives anti-HTN treatment } \\
\hline Yes & 503 & 60.5 \\
\hline
\end{tabular}




\section{Cureus}

Number of anti-HTN drugs

1

Had anti-HTN treatment today

Yes

No

Type of drug

ARA-II

Beta blocker

Calcium antagonist

ACE inhibitor

Thiazide

ARA-II + beta blocker

ARA-II + calcium antagonist

ARA-II + thiazide

$5 \quad 1$

ARA-II + ACE inhibitor

8

ACE + beta blocker

3

0.6

ACE + calcium antagonist

8

$\mathrm{ACE}+$ thiazide

18

Triple therapy, quadruple therapy

8,3

TABLE 1: Characteristics of the respondents and the antihypertensive treatment they received

${ }^{*}$ Median and range

HTN = hypertension; ARA-II = angiotensin II receptor antagonist; ACE = angiotensin converting enzyme

Figure 1 shows the percentage of people taking antihypertensive treatment and having comorbidities. 


\section{Cureus}

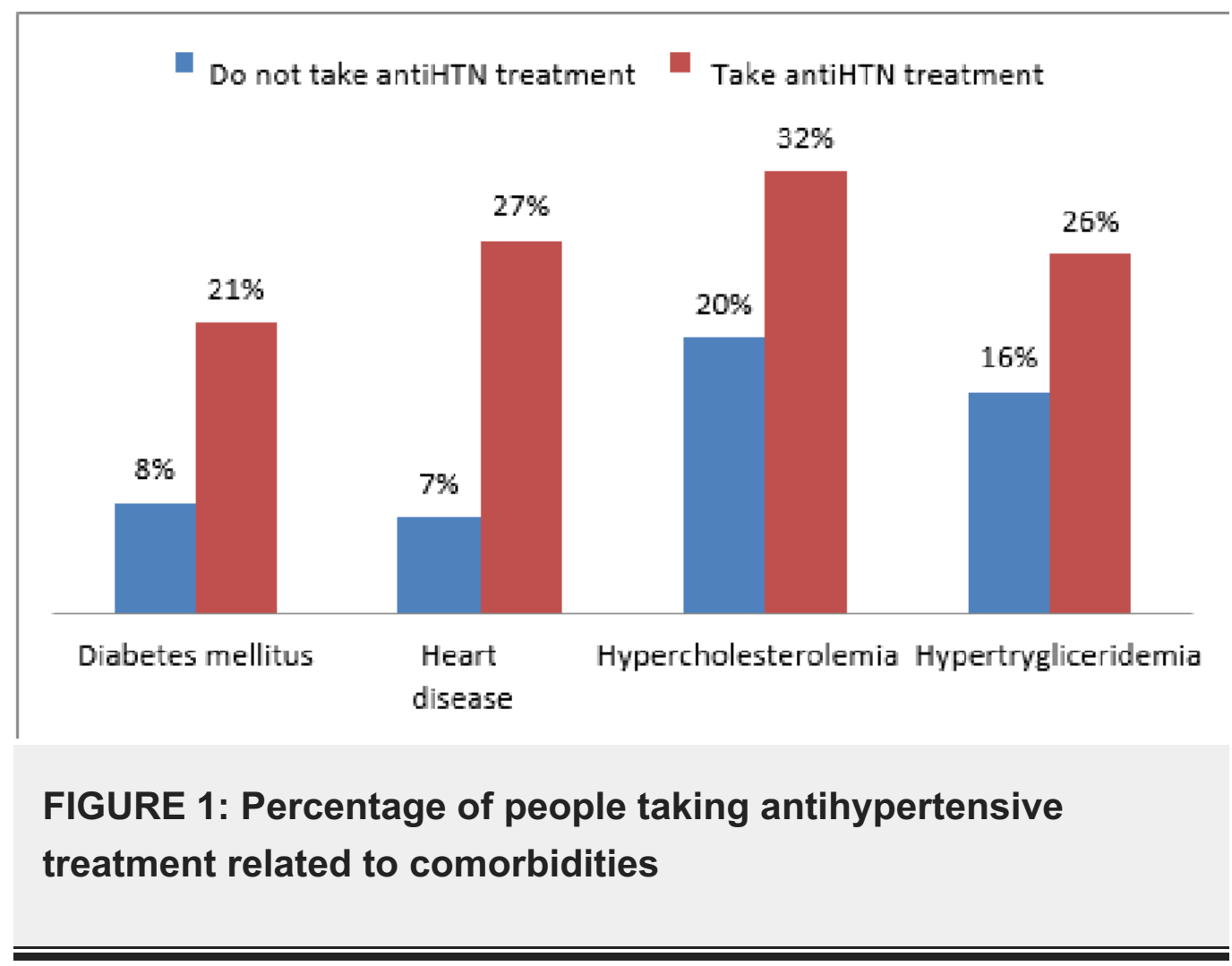

Antihypertensive treatment was positively correlated to the patient's age $(p<0.001)$ and known diagnosis of the following medical conditions and treatment timing: diabetes mellitus ( $p=$ 0.001 and $<0.001$, respectively), heart disease ( $p<0.001$ and $<0.001$, respectively), hypercholesterolemia ( $\mathrm{p}=0.017$ and $<0.001$, respectively), and hypertriglyceridemia $(\mathrm{p}=0.043$ and $<0.001$, respectively). Moreover, frequency of antihypertensive medication use decreased when performing physical activity $(\mathrm{p}<0.001)$ and any sports $(\mathrm{p}=0.004)$. See Table 2 .

\section{Variable}

\section{Gender}

Female

Male

Age (years)*

Diabetes mellitus

Diagnosed

Receives treatment

Heart disease

Diagnosed

Receives treatment

Hypercholesterolemia
Patients with HTN N (\%)

cPR $(95 \% \mathrm{Cl})$

$p$ value

With treatment Without treatment

$306(60.8)$

$202(61.4)$

$0.99(0.77-1.28)$

0.943

$127(38.6)$

$50.4(16.4)$

$1.02(1.01-1.03)$

$<0.001$

$60.2(15.0)$

$106(21.1)$

$26(7.9)$

$1.42(1.23-1.63)$

0.001

94 (18.7)

$16(4.9)$

$1.51(1.25-1.82)$

$<0.001$

$138(27.4)$

$22(6.7)$

$1.59(1.40-1.80)$

$<0.001$

$112(22.3)$

11 (3.3)

$1.65(1.45-1.88)$

$<0.001$ 


\section{Cureus}

$\begin{array}{lcccc}\text { Diagnosed } & 160(31.8) & 67(20.4) & 1.24(1.04-1.49) & 0.017 \\ \text { Receives treatment } & 105(20.9) & 30(9.1) & 1.36(1.23-1.52) & <0.001\end{array}$

Hypertriglyceridemia

Diagnosed

Receives treatment

Other disease

Chronic

Cardiovascular

Performs

Physical activity

137 (27.2)

$72(14.3)$
$155(47.1)$

89 (27.1)

$1.24(1.01-1.52) \quad 0.043$

$1.39(1.25-1.53) \quad<0.001$

$1.02(0.88-1.20) \quad 0.764$

$1.14(0.94-1.39) \quad 0.181$

$20(6.4)$

$0.69(0.58-0.82)<0.001$

$0.70(0.54-0.89) \quad 0.004$

\section{TABLE 2: Bivariate analysis of factors associated with receiving antihypertensive}

\section{treatment}

Confidence interval $(95 \% \mathrm{Cl})$ and $\mathrm{p}$ value obtained from generalized linear models with Poisson distribution, log link function, and headquarters of the respondent as clusters.

HTN = hypertension; $c P R=$ crude prevalence ratio

*Mean and standard deviation

When performing the multivariate model, increased age in years was associated with higher frequency of medication use (aPR: $1.01 ; 95 \%$ CI: 1.007 to 1.017 ; p value < 0.001 ). Similarly, antihypertensive medication use was more frequent in patients who were receiving treatment for diabetes (aPR: $131 ; 95 \%$ CI: 1.11 to $1.552 ; p$ value $=0.001$ ) and in those with heart disease (aPR: 1.38 ; $95 \%$ CI: 1.26 to 1.51 ; $\mathrm{p}$ value $<0.001$ ). However, those doing physical activity took less medication (aPR: 0.80 ; $95 \%$ CI: 0.70 to $0.92 ; p$ value $=0.001$ ), adjusted for receiving treatment for hypercholesterolemia or hypertriglyceridemia (Table 3). 


\section{Cureus}

\begin{tabular}{|c|c|c|}
\hline Variable & aPR (95\% Cl) & $\mathrm{p}$ value \\
\hline Age (years) ${ }^{*}$ & $1.01(1.007-1.017)$ & $<0.001$ \\
\hline \multicolumn{3}{|l|}{ Receives treatment for: } \\
\hline Diabetes mellitus & $1.31(1.11-1.55)$ & 0.001 \\
\hline Heart disease & $1.38(1.26-1.51)$ & $<0.001$ \\
\hline Hypercholesterolemia & $1.08(0.90-1.29)$ & 0.398 \\
\hline Hypertriglyceridemia & $1.16(0.98-1.37)$ & 0.075 \\
\hline Performs physical activity & $0.80(0.70-0.92)$ & 0.001 \\
\hline
\end{tabular}

\section{TABLE 3: Multivariate analysis of factors associated with receiving antihypertensive treatment}

Confidence interval $(95 \% \mathrm{Cl})$ and $\mathrm{p}$ value obtained from generalized linear models with Poisson distribution, log link function, and headquarters of the respondent as clusters.

aPR = adjusted prevalence ratio

*Mean and standard deviation

\section{Discussion}

Hypertension represents a worldwide epidemic, with a global prevalence of 40\% [15]. Hypertension can cause direct and indirect complications, including cardiovascular disease, and accounts for 9.4 million annual deaths [15-19]. Based on these facts, it is of utmost importance to treat hypertension to reduce or prevent serious complications [20].

In our study, only $60 \%$ of hypertensive patients were receiving treatment. This is consistent with other studies that show hypertensive patients have poor adherence to treatment [17-19], which may be the primary cause of uncontrolled hypertension [16]. On the other hand, there may be multiple reasons for nonadherence to medications such as poor access to healthcare, cost of medicine, etc. These data can help physicians develop strategies to improve medication adherence by identifying the profile of patients who do not comply with treatment [20] to generate intervention policies and improve care in this patient population. A meta-analysis of 22 studies by Nielsen et al. showed that social and economic factors are the most reported factors of nonadherence in low- and middle-income countries, followed by condition-related factors (e.g., comorbidities and medication side effects) and patient-related factors (e.g., knowledge and attitude) [15].

Our study showed that patients with increased age are more likely to be on antihypertensive medication. Moreover, hypertensive patients have a higher rate of comorbidities, which makes it more difficult to address and avoid complications [21-22]. Gender showed no influence on the pharmacological control of hypertension in our study, which conflicts with reports from many other studies [22-23] that display less compliance in males. However, there are other studies that align with our gender findings [21]. Therefore, we recommend further study of the association between these two variables in the pharmacological management of hypertensive 
patients.

Our study also revealed that carrying a diagnosis and receiving treatment for diabetes mellitus or heart disease increases the frequency of antihypertensive medication use. This is consistent with studies showing that patients tend to take their medications to avoid similar complications [24], especially if they have concurrent heart diseases, to avoid cardiovascular complications [25].

Finally, this study showed that physical activity was associated with a lower frequency of antihypertensive medication use. This may be because patients with constant physical activity tend to improve their blood pressure, as shown in some revisions of the subject [26]. This is further supported by a meta-analysis of randomized controlled trials showing that aerobic exercise of at least four weeks significantly reduced resting and ambulatory blood pressure [2728].

Our study has a selection bias because the sample was not randomized, so confidence intervals are used merely for comparison with other studies and estimation of the results obtained by the amplitude range. Furthermore, the data we collected is mainly based on patient surveys, which may be less accurate than patient records. On the other hand, this study has multiple strengths: it reflects data from multiple health centers in Peru; the most important variables related to the disease were considered; and it is the first report in our area that reviews the association of antihypertensive medication use with patient characteristics.

\section{Conclusions}

Based on revised data, we conclude that hypertensive patients in Peru have a poor medication adherence. Increasing age, diabetes, and heart disease are associated with the increased use of antihypertensive medications. On the other hand, increased physical activity decreases the use of antihypertensive medications. All these factors should be considered during efforts to improve programs on patient compliance.

Further studies are needed to identify the factors affecting medication adherence in the hypertensive patients of Peruvian health facilities. This will enable us to create a strategy or solution for each of these factors, subsequently improve medication compliance, and finally, reduce the complications from hypertension.

\section{Additional Information \\ Disclosures}

Human subjects: Consent was obtained by all participants in this study. Hospital Nacional San Bartolome and Hospital Regional de Lambayeque issued approval N/A. Animal subjects: All authors have confirmed that this study did not involve animal subjects or tissue. Conflicts of interest: In compliance with the ICMJE uniform disclosure form, all authors declare the following: Payment/services info: All authors have declared that no financial support was received from any organization for the submitted work. Financial relationships: All authors have declared that they have no financial relationships at present or within the previous three years with any organizations that might have an interest in the submitted work. Other relationships: All authors have declared that there are no other relationships or activities that could appear to have influenced the submitted work.

\section{Acknowledgements}

The following three authors contributed equally to this article: Christian R. Mejia, Virgilio E. 


\section{References}

1. Ezzati M, Lopez AD, Rodgers A, et al.: Selected major risk factors and global and regional burden of disease. Lancet. 2002, 360:1347-60. 10.1016/S0140-6736(02)11403-6

2. Stoll AI: Artículo de revision: Hipertensión arterial resistente [Article in Spanish and English] . Acta Med Per. 2013, 30:92-5.

3. Mancia G, De Backer G, Dominiczak A, et al.: 2007 Guidelines for the management of arterial hypertension: the task force for the management of arterial hypertension of the European Society of Hypertension (ESH) and of the European Society of Cardiology (ESC). J Hypertens. 2007, 25:1105-87. 10.1097/HJH.0b013e3281fc975a

4. Chobanian AV, Bakris GL, Black HR, et al.: The seventh report of the joint national committee on prevention, detection, evaluation, and treatment of high blood pressure. JAMA. 2003, 289:2560-71. 10.1001/jama.289.19.2560

5. James PA, Oparil S, Carter BL, et al.: 2014 evidence-based guideline for the management of high blood pressure in adults: Report from the panel members appointed to the Eighth Joint National Committee (JNC 8). JAMA. 2014, 311:507-20. 10.1001/jama.2013.284427

6. Stewart IM: Relation of reduction in pressure to first myocardial infarction in patients receiving treatment for severe hyper tension. Lancet. 1979, 1:861-5.

7. Turnbull F: Effects of different blood-pressure-lowering regimens on major cardiovascular events: results of prospectively-designed overviews of randomised trials. Lancet. 2003, 362:1527-35.

8. Staessen JA, Wang JG, Thijs L: Cardiovascular prevention and blood pressure reduction: a quantitative overview updated until 1 March 2003. J Hypertens. 2003, 21:1055-76.

9. Bryce-Moncloa A: Actualización y raciocinio del mejor tratamiento antihipertensivo [Article in Spanish and English]. An Fac Med. 2010, 71:251-5.

10. Waeber B, Burnier M, Brunner HR: Compliance with antihypertensive therapy . Clin Exp Hypertens. 1999, 21:973-85. 10.3109/10641969909061025

11. Romero FL, Alonso VB, Arcos FS, et al.: Guías de práctica clínica de la Sociedad Española de Cardiología en hipertensión arterial [Article in Spanish and English]. Rev Esp Cardiol. 2000, 53:66-90. 10.1016/S0300-8932(00)75065-2

12. De la Sierra A, González-Segura D: Risk factors in hypertensive patients without previous cardiovascular events [Article in Spanish and English]. Med Clin. 2011, 136:559-64. 10.1016/j.medcli.2010.11.025

13. Barreto MS, Reiners AAO, Marcon SS: Knowledge about hypertension and factors associated with the non-adherence to drug therapy. Rev Lat Am Enfermagem. 2014, 22:491-8. 10.1590/0104-1169.3447.2442

14. World Health Organization: Reducing risks and preventing disease: population-wide interventions. Global status report on noncommunicable diseases 2010. Dr. Ala Alwan (ed): WHO Press, Geneva, Switzerland; 2011. 47-60.

15. Nielsen JO, Shrestha AD, Neupane D, Kallestrup P: Non-adherence to anti-hypertensive medication in low- and middle-income countries: a systematic review and meta-analysis of 92443 subjects. J Hum Hypertens. 2017, 31:14-21. 10.1038/jhh.2016.31

16. Lee CY, Huang CC, Shih HC, Huang KH: Factors influencing antihypertensive medication compliance in Taiwan: a nationwide population-based study. Eur J Prev Cardiol. 2013, 20:9307. $10.1177 / 2047487312451252$

17. Goverwa TP, Masuka N, Tshimanga M, et al.: Uncontrolled hypertension among hypertensive patients on treatment in Lupane District, Zimbabwe, 2012. BMC Res Notes. 2014, 7:703. 10.1186/1756-0500-7-703

18. Wilinski J, Dabrowski M: Medication adherence in hypertensive patients of different cardiovascular risk treated in primary health care. Przegl Lek. 2013, 70:377-80.

19. de Souza CS, Stein AT, Bastos GA, Pellanda LC: Blood pressure control in hypertensive patients in the Hiperdia Program: a territory-based study. Arq Bras Cardiol. 2014, 102:571-8.

20. Bailey JE, Hajjar M, Shoib B, et al.: Risk factors associated with antihypertensive medication nonadherence in a statewide Medicaid population. Am J Med Sci. 2014, 348:410-5. 10.1097/MAJ.0b013e31825ce50f

21. Varleta P, Akel C, Acevedo M, et al.: Prevalencia y determinantes de adherencia a terapia 
antihipertensiva en pacientes de la Región Metropolitana. Rev Med Chil. 2015, 143:569-76.

22. Chacón J, Sandoval D, Muñoz R, Romero T: Assessment of blood pressure control and adherence in hypertensive patients followed in the Cardiovascular Health Program (CHP). Association with clinical, socioeconomic and psychosocial characteristics [Article in Spanish and English]. Rev Chil Cardiol. 2015, 34:18-27. 10.4067/S0718-85602015000100002

23. Velandia-Arias A, Rivera-Álvarez LN: Self-care agency and adherence to treatment in people having cardiovascular risk factors. Rev Salud Pública. 2009, 11:538-48. 10.1590/S012400642009000400005

24. Mogensen CE: Long-term antihypertensive treatment inhibiting progression of diabetic nephropathy. Br Med J (Clin Res Ed). 1982, 285:685-8. 10.1136/bmj.285.6343.685

25. Orozco-Beltrán D, Brotons C, Moral I, et al.: Factors affecting the control of blood pressure and lipid levels in patients with cardiovascular disease: the PREseAP Study [Article in Spanish and English]. Rev Esp Cardiol. 2008, 61:317-21. 10.1157/13116661

26. Mancia G, Fagard R, Narkiewicz K, et al.: Guía de práctica clínica de la ESH/ESC para el manejo de la hipertensión arterial (2013) [Article in Spanish]. Rev Esp Cardiol. 2013, 66:880.e1-880.e64. 10.1016/j.recesp.2013.07.016

27. Cornelissen VA, Fagard RH: Effects of endurance training on blood pressure, blood pressureregulating mechanisms, and cardiovascular risk factors. Hypertension. 2005, 46:667-75. 10.1161/01.HYP.0000184225.05629.51

28. Molmen-Hansen HE, Stolen T, Tjonna AE, et al.: Aerobic interval training reduces blood pressure and improves myocardial function in hypertensive patients. Eur J Prev Cardiol. 2012, 19:151-60. 10.1177/1741826711400512 